\title{
A formação de professores para crianças de 0 a 10 anos: Modelos em debate*
}

\author{
Maria Malta Campos **
}

\begin{abstract}
RESUMO: O texto discute as questões envolvidas na definição de um novo perfil para os professores de educação infantil e das quatro primeiras séries do Ensino Fundamental. Mostra como, historicamente, constituiram-se dois modelos diferentes de professores: 0 do professor generalista, formado no nível médio, e o do professor especializado por disciplinas, formado no nível superior. O primeiro inclui aqueles que trabalham com a faixa etária de 0 a 10 anos, sendo que na educação infantil existem ainda diferenças entre os professores de crianças de pré-escolas e educadores que trabalham em creches, no Brasil em sua maioria leigos. Tendo em vista as mudanças legais e as reformas dos sistemas educacionais no país, o artigo discute aspectos ligados: às relações entre teoria e prática; entre conhecimentos voltados para os conteúdos do ensino e aqueles relativos às características de desenvolvimento dos educandos; aos níveis de ensino nos quais se insere a formação de professores; às especializações pelas subfaixas etárias entre 0 e 10 anos; e à preparação para o trabalho com os pais e a comunidade. Finalmente, enfatiza a importância de se pensar soluções para o período de transição em direção aos novos padrões definidos pela legislação.
\end{abstract}

Palavras-chave: Professores de educação infantil, professores de $1^{\circ}$ a $4^{\circ}$ séries do Ensino Fundamental, formação de professores

\footnotetext{
* Trabalho apresentado no Seminário Temático "Formação no ensino médio de professores para o Ensino Fundamental: Educação infantil e séries iniciais". V Congresso Estadual sobre Formação de Educadores. Águas de São Pedro, 16 a 20 de novembro de 1998.

** Pesquisadora na Fundação Carlos Chagas e Professora na PUC de São Paulo. Email: medadand@usp.br
} 


\section{Apresentação}

A nova legislação educacional e as reformas que vêm sendo introduzidas nos sistemas educacionais estaduais e municipais nos últimos anos trouxeram consigo uma nova perspectiva para a abordagem da formação e da carreira dos professores ${ }^{1}$, que abre possibilidades muito interessantes.

Talvez pela primeira vez em nosso país, começamos a pensar um perfil de educador adequado às características e necessidades de alunos em diferentes fases de seu desenvolvimento. Ou seja, começamos a pensar na criança, no adolescente, no jovem, no adulto que se encontra escondido atrás da palavra "aluno". Ao fazer isso, fica mais fácil também pensar no menino e na menina, na criança de diferentes origens sociais, étnicas, regionais, na criança do campo e na criança da cidade, e assim por diante. Podemos pensar nos alunos em sua diversidade e em suas contínuas mudanças, as quais refletem as transformações nas condições de vida da população e nos valores que informam a socialização das novas gerações nos diversos espaços fora da escola: na família, na cidade, nos meios de comunicação, nos grupos de pares, no trabalho.

Essa nova perspectiva permite também que alguns espaços de discussão acadêmica, até agora segregados, passem a conversar entre si. Por exemplo, as áreas de formação de professores e de educação infantil, até recentemente desenvolveram suas reflexões em paralelo.

$\mathrm{Na}$ área de educação infantil, o debate sobre a formação de professores, ou de educadores como alguns ainda preferem chamar, sempre partiu de uma ênfase muito grande sobre as características do desenvolvimento infantil na faixa de 0 a 6 anos. $O$ conhecimento que existe sobre essa etapa do desenvolvimento humano - e mais recentemente, sobre como as crianças pequenas se desenvolvem em ambientes coletivos de acolhimento e educação - tem sido, na maioria dos países, um dos pressupostos básicos para a formulação de propostas pedagógicas para essa faixa etária e para o delineamento da formação prévia e em serviço dos profissionais que trabalham nas creches e nas pré-escolas. A consideração do duplo aspecto "educar e cuidar" na definição de programas e do perfil do educador decorre dessa importância conferida às necessidades de desenvolvimento da criança pequena (Campos 1994).

Mais recentemente, algumas linhas de análise têm dado ênfase ao conceito de socialização em espaços alternativos à família como sendo 
uma forma de abordar o processo educativo que responde melhor à necessidade de considerar a criança de forma integrada e sem privilegiar um aspecto de seu desenvolvimento em detrimento de outros (por exemplo, o aspecto cognitivo). Essa abordagem corresponde a experiências realizadas nos países escandinavos, especialmente na Dinamarca (Haddad 1997).

De qualquer forma, talvez não seja arriscado afirmar que a discussão mais geral que se trava hoje sobre a formação e a carreira dos professores tenha muito a lucrar com a contribuição da literatura e das experiências práticas na área de educação infantil, que até agora não têm circulado muito fora dessa especialidade.

Esse é um dos motivos pelos quais adoto a expressão "professores de crianças de 0 a 10 anos", porque, afinal, é disso que se trata quando pensamos no que prescreve a nova LDB, ao incluir a educação em creches e pré-escolas na educação básica e ao definir o mesmo tipo de formação para os professores que atuam na educação infantil e nas quatro primeiras séries do Ensino Fundamental.

\section{As diversas "ordens" de ensino e seus respectivos profissionais}

Anne-Marie Chartier (1998) ajuda-nos a pensar a estruturação do sistema formal de ensino com base na análise que realiza sobre a realidade francesa, a qual tem muitas semelhanças com a organização que historicamente assumiu a escola brasileira. Resumo a seguir os principais pontos de seu texto com o propósito de subsidiar essa reflexão, e não com a pretensão de analisar a reforma francesa.

Ela mostra como, na França, desde a criação do sistema público de ensino, coexistiram dois corpos hierárquicos de funcionários: um correspondente ao ensino primário de massa, com seus professores formados em instituições próprias e seu tipo específico de carreira; outro corpo de funcionários correspondia ao ensino secundário - o liceu -, o qual não era concebido como um ensino de massa, sendo acessível apenas a uma parcela da população, com seus professores formados em universidades. Cada um desses corpos de funcionários sempre teve identidades profissionais e imagens públicas muito bem definidas. Esses corpos hierárquicos, com seus lugares de formação, seus perfís profissionais, 
seus sistemas de ingresso e progressão na carreira, suas organizações sindicais, seu ethos, sua identidade pública, incluindo-se aí não somente os professores, mas também os inspetores e demais profissionais da educação, constituíram, na interpretação da autora, duas diferentes "ordens" até os anos do pós-guerra: a ordem do primário e a ordem do secundário. A elas correspondia também um determinado padrão de prédios escolares, pois só muito mais tarde o primeiro ciclo do secundário deixou de integrar o prédio do liceu e foi se juntar ao primário.

A ordem do primário era composta pelos professores funcionários do Estado, formados nas escolas normais primárias superiores, as quais atendiam a alunos de um só sexo. Os egressos dessas escolas podiam lecionar em escolas primárias e primárias superiores (uma extensão do curso primário), nas quais os professores eram especializados apenas em duas áreas: letras ou ciências. A ênfase na escola normal era sobre a metodologia de ensino, com aulas práticas nas escolas de aplicação anexas: era a formação dos "professores pedagogos". Nas escolas femininas de formação havia também uma pré-escola anexa. Como nota a autora, a escola pública primária era uma escola do sucesso escolar justamente porque era uma escola segregada, desenhada para as classes populares.

A ordem do secundário foi montada sobre uma lógica diferente, sendo um nível de ensino concebido para alunos de outra origem social, visando a uma formação acadêmica que conduzisse ao Ensino Superior e às profissões de maior prestígio social. Seus professores são formados em cursos superiores especializados por conteúdo das diversas áreas do conhecimento, havendo uma ênfase relativamente menor nos aspectos didáticos e de prática de ensino: é a formação dos "professores eruditos".

Com o aumento de cobertura dos cursos posteriores ao primário no período pós-guerra, há uma diversificação de trajetórias escolares ("fileiras"), algumas conduzindo a cursos profissionalizantes de nível secundário e outras ao secundário acadêmico com direito de acesso ao nível superior.

O processo de democratização do ensino na França vai fazer com que as diferenças entre as duas ordens progressivamente se diluam: a escolarização obrigatória se estende, a população escolar cresce e, em decorrência, o mercado de trabalho para os professores amplia-se consideravelmente. Há uma massificação da profissão e a ordem do secundário torna-se cada vez mais parecida com a ordem do primário. Os professores traduzem essas mudanças nas queixas 
sobre uma suposta queda no nível de ensino e a pressão da demanda transfere-se para a entrada na universidade.

As tensões geradas por esse processo revelam-se nas resistências a reformas como a que levou à criação, em 1989, dos Institutos Universitários de Formação de Mestres - IUFM, que agrupou a formação de professores para o primário e o secundário na mesma instituição. Essa reforma mudou a concepção de formação dos professores primários, tornando-a mais parecida com aquela dos professores secundários, dando maior ênfase à formação teórica. Por sua vez, mudou também a imagem dos professores secundários, acabando com a distância que lhes conferia superioridade perante os professores primários. A mudança no perfil dos professores formadores também causou celeuma, pois se lamentava que os professores da universidade estivessem sendo substituídos pelos pedagogos dos IUFMs e a formação geral desses profissionais comprometida por esse motivo.

Anne-Marie Chartier não se detém muito a respeito dos professores da escola maternal, a pré-escola francesa. Um outro autor, Daniel Verba (1993), ajuda-nos nesse ponto, refletindo sobre os dois perfis de profissionais que atuam na educação infantil na França: os professores da escola maternal, na área educacional, e os educadores das creches, vinculados ao setor da saúde e da assistência social.

Ele mostra como também nesse campo é possível identificar dois perfis profissionais bem diferentes: a antiga "jardineira" ou professora de jardim-de-infância, formada inicialmente na tradição froebeliana, mas com uma identidade cada vez mais semelhante à do professor primário, na medida em que as escolas maternais foram praticamente universalizadas na França; e a educadora de creche, instituição criada inicialmente para o segmento mais pobre da população, que se disseminou após os anos 60 , mas com vinculação institucional e características muito diferentes da escola maternal. Essa segunda profissão foi reorganizada por uma lei de 1973, com o nome de "educadores de criança pequena", voltados para o atendimento de crianças de 0 a 6 anos "momentânea ou definitivamente separadas de suas famílias", aí incluindo-se as creches (Verba 1993, p. 15).

O autor insere seu estudo no campo da sociologia das profissões, procurando entender como se processa a "construção social" das profissões e de sua "representação social", na acepção de Bourdieu (1980, apud Verba 1993).

Daniel Verba também cita uma entrevista de Pierre Bourdieu ao jornal Le Monde, na qual o autor se refere às profissões ligadas ao campo so- 
cial como fazendo parte da "mão esquerda do Estado", profissões vinculadas aos ministérios ditos "gastadeiros" (educação, bem-estar, justiça etc.), opostos à "mão direita do Estado" (Ministério das Finanças, por exemplo). Para Bourdieu, "a mão esquerda do Estado" guarda as marcas das lutas sociais do passado, sendo que muitos movimentos sociais do presente refletem essa oposição entre o que ele chama de "pequena nobreza de Estado" contra a "grande nobreza de Estado" (Bourdieu 1992 apud Verba 1993).

Mas mesmo no interior dessa "mão esquerda do Estado" e dessa "pequena nobreza de Estado" são grandes as diferenças de origem, de identidade e de status entre as profissões, como sabemos. Assim, quando consideramos os profissionais da educação, confirma-se por toda a parte a regra que estabelece que quanto menor a criança a se educar, menor o salário e o prestígio profissional de seu educador e menos exigente o padrão de sua formação prévia.

Acompanhando essas características, tanto em função dos salários mais baixos como das concepções tradicionais sobre o papel da mulher na sociedade, o percentual do contingente feminino é tão mais alto quanto mais se baixa a faixa etária do alunado: segundo dados de 1995, esses percentuais, para o conjunto de países, era de $94 \%$ no nível pré-escolar, $58 \%$ no primário e $47 \%$ no secundário. Para os países da América Latina, essas porcentagens eram respectivamente de $97 \%$ no pré, $77 \%$ no primário e $46 \%$ no secundário (Unesco 1998, p. 114).

Ou seja, até mesmo no interior dessa faixa etária de 0 a 10 anos há, em quase todos os países, uma subierarquização dos profissionais que é preciso levar em consideração no momento de analisar as propostas de reforma em pauta.

\section{Concepções de formação de professores no contexto das reformas educacionais}

Outro autor que nos ajuda a pensar sobre as propostas de inovação nesse campo é Thomas Popkewitz. Em capítulo introdutório aos estudos de caso incluídos no livro por ele organizado sobre o tema (Popkewitz 1992), escrito em conjunto com Miguel Pereyra, os autores desenvolvem uma proposta teórico-metodológica de abordagem, inspirada principalmente na obra de Foucault. 
Nessa abordagem, as mudanças introduzidas nos modelos de formação de professores são vistas no contexto das inovações propostas pelas reformas educacionais nos diversos países, entendidas estas como parte das transformações nos sistemas de regulação social que caracterizam as sociedades capitalistas atuais. Os autores consideram que, após a ênfase nas reformas dos currículos, a formação de professores é agora o aspecto focalizado com prioridade pelas reformas promovidas em diversos países. Segundo suas palavras, "os esforços nacionais de reforma fazem parte e ajudam a configurar as relações de poder e as regulações que se produzem dentro e através das sociedades" (Popkewitz e Pereyra 1992, p. 17).

Para esses autores, o conteúdo e a organização da formação do professorado são centrais para os objetivos de modernização dos sistemas de ensino. Esses programas de reforma constituem também respostas às transformações ocorridas em diversos setores da vida social. Entendê-los como parte de mudanças nos sistemas de regulação significa considerá-los em sua dimensão de difusão de novas formas de pensamento e ação, de construção de subjetividades e estilos cognitivos, como diria Foucault. Segundo essa perspectiva, o poder está "intrinsecamente ligado a regras, normas e estilos de pensamento mediante os quais os indivíduos falam, pensam e atuam na produção de seu mundo cotidiano" (Popkewitz e Pereyra 1992, p. 41).

A análise das reformas na formação de professores, segundo Popkewitz e Pereyra (1992, p. 42), deve se basear em duas noções de poder: a primeira - "poder como soberania" - considera os atores sociais e os interesses que representam como forças que atuam em um determinado campo; a segunda - "poder como conhecimento" - enfatiza o poder como função do conhecimento, analisando os modelos de comunicação, a produção dos discursos técnicos e acadêmicos, as normas e regras estabelecidas para se pensar a educação profissional.

Os estudos de caso sobre Portugal, Espanha, Islândia, Finlândia, Suécia, Estados Unidos e Reino Unido ressaltam três características das reformas introduzidas na formação de professores: a primeira é o fato de as reformas estarem refletindo as transformações sociais, econômicas, culturais e políticas ocorridas nesses países, especialmente as mudanças ligadas à globalização econômica, aos novos perfis demográficos, às tensões étnicas e culturais e à reorganização do Estado; segundo, elas se caracterizam por uma crescente racionalização na operação dos sistemas educacionais, com ênfase em aspectos como produtividade e competência; terceiro, os diversos casos estudados mostram a importân- 
cia que adquiriram os órgãos de cooperação internacional, como a Organização para a Cooperação e o Desenvolvimento Econômico (OCDE) e a União Européia, na implementação de tais reformas.

É interessante perceber como muitos desses aspectos são comuns às mudanças às quais estamos assistindo em nosso país nos últimos anos. Também aqui as transformações econômicas criam novas demandas para o sistema educacional e o redimensionamento do Estado leva a esforços no sentido de introduzir maior racionalidade e conseguir ganhos de produtividade nos sistemas escolares. Os organismos internacionais, como por exemplo o Banco Mundial, também desempenham entre nós um papel cada vez mais decisivo.

As reformas utilizam discursos e propõem práticas muito semeIhantes nos vários países. Assim, os estudos realizados sobre outras realidades nos ajudam a pensar e até a antecipar os fenômenos que ocorrem em nosso entorno.

\section{A situação brasileira: Antecedentes e características}

No Brasil, as mudanças sociais e econômicas também provocaram transformações importantes nos sistemas de ensino e, em conseqüência, no mercado de trabalho e no perfil dos professores.

Só para lembrar as mudanças mais importantes, hoje, a maioria da população vive em cidades, sendo algumas delas metrópoles entre as mais populosas do mundo. As famílias modificaram-se bastante, com um número relativamente menor de filhos, com uma maior presença de mães chefes de família, maior presença da mulher-mãe no mercado de trabalho e, nos últimos anos, um agravamento da exclusão social, do desemprego e da violência. Com a enorme expansão das matrículas na escola pública, a população escolar reproduz as características do conjunto da população, com exceção dos segmentos de renda mais alta que pagam escolas particulares e que representam uma porcentagem pequena dos alunos do Ensino Fundamental no país.

Ao mesmo tempo em que se multiplicaram as matrículas, multiplicaram-se também os postos de trabalho para professores. Em 1994, estes somavam mais de 280 mil funções docentes na pré-escola e mais de 1 milhão e 300 mil no Ensino Fundamental (Gatti 1997). A expansão de 
vagas, como se sabe, foi acompanhada de perda de qualidade em muitos casos, com diminuição de salário real, classes superlotadas, aumento do número de turnos diários nas escolas das grandes cidades, entre outros problemas. O perfil social do professorado modificou-se, fazendo com que as crianças de baixa renda tenham como professores pessoas de um nível social não muito diferente ao delas (Gatti, Esposito e Silva 1994). Por outro lado, tal como os demais movimentos sindicais, a mobilização dos professores também perdeu força, lutando para encontrar novos caminhos de expressão na sociedade.

É sobre esse cenário que vão incidir as reformas educacionais no país. O primeiro marco, a nova Constituição, introduz mudanças importantes, principalmente no que se refere às creches e pré-escolas, incluídas no âmbito da educação. As reformas estaduais e municipais, a partir da redemocratização do país na década de 1970, procuram dar respostas aos pontos de estrangulamento dos sistemas: índices altos de repetência, baixa cobertura da educação infantil e do segundo grau, exclusão precoce, professores sem formação prévia, currículos e material didático desatualizado, falta de canais de participação da comunidade na gestão da escola.

Mas é a partir da aprovação da nova lei da educação em 1996 que vão se dar as mudanças mais amplas, que abarcam todo o país. São mudanças no sistema de financiamento, no currículo nacional, nos sistemas de avaliação, na utilização da informática e da televisão, na organização da gestão, no estabelecimento de parcerias com organizações não-governamentais, entre outras. Ou seja, vivemos um momento de intensa efervescência na educação, cujos velhos problemas finalmente ganharam ampla visibilidade e adquiriram prioridade na agenda pública.

Esse é o contexto no qual incidem as novas propostas de formação de professores. Podemos tentar entendê-lo com a ajuda dos esquemas interpretativos dos autores mencionados anteriormente.

\section{As diferentes "ordens" hierárquicas entre nós}

Aqui também tivemos, ao longo do tempo, a constituição de pelo menos três diferentes corpos hierárquicos profissionais no ensino: a professora e o professor de $1^{\underline{a}}$ a $4^{\underline{a}}$ série, formados no curso Normal secundário e, em anos mais recentes, no curso de pedagogia; com a mesma for- 
mação, a professora e o professor de pré-escola, sendo que muitas vezes a trajetória desses profissionais se inicia na pré-escola para depois "progredir" nas primeiras séries do Ensino Fundamental, o antigo primário. São professores generalistas, a maioria mulheres; participam muitas vezes de sindicatos com orientação mais moderada e assistencialista.

A segunda ordem, aqui como na França, constitui-se dos professores especialistas, formados em curso superior, lecionando disciplinas específicas a partir da $5^{\mathrm{a}}$ série, antiga $1^{\text {a }}$ série do ginásio, com formação prévia que privilegia o conteúdo, participando geralmente de sindicatos mais combativos e politizados. Seu papel tradicional foi definido no curso secundário público de elite, de cunho acadêmico, que garantia o acesso ao curso superior. Embora hoje esse perfil tenha se perdido na realidade, ele continua presente nas representações sociais e nos debates sobre as reformas educacionais.

Mas temos aqui também uma terceira ordem, a dos educadores leigos, mal pagos, muitas vezes sem vínculo formal de emprego. Estão presentes na maioria das creches, tanto públicas como conveniadas, nas escolas rurais unidocentes das regiões mais pobres, nas escolas comunitárias das favelas de cidades do Nordeste e do Norte, nos programas pré-escolares de baixo custo, ou como monitores de educação de adultos. Essas educadoras, na sua maioria mulheres, grande parte delas negras, muitas vezes estão vinculadas a programas educacionais fora da área de educação, ligados a órgãos de assistência social, a entidades filantrópicas ou comunitárias. Atendem os filhos da pobreza, aquelas crianças e adolescentes que costumam ser rejeitados pelos sistemas formais de ensino.

É interessante observar como essas três "ordens" sobreviveram a sucessivas reformas legais e organizacionais: a criação do ensino de $1^{\circ}$ grau em 1971, com a junção do primário e do ginásio, não interferiu nelas; a implantação dos programas compensatórios de educação pré-escolar na década de 1970 tampouco, sendo que muitas vezes até incentivou o recrutamento de professoras leigas; o aumento de professores primários formados no curso de pedagogia também não alterou o perfil geral desses profissionais; as mudanças sucessivas introduzidas no ensino médio, por sua vez, não chegaram a modificar essas carreiras.

Assim, esses corpos hierárquicos sobreviveram a todas essas mudanças, incorporando as transformações sociais no seu perfil - perda de prestígio, origem social diversa, condições de trabalho mais difíceis - mas sem perder seus lugares na estratificação interna da profissão. 
Como serão afetados pelas reformas agora propostas é algo que ainda teremos de avaliar.

\section{Modelos de formação em debate}

Assim, é nesse contexto, ao mesmo tempo de permanência e de mudança, que podemos pensar as propostas de reforma. Penso que elas podem ser debatidas a partir de alguns aspectos de caráter mais estruturante, explicitados a seguir, os quais conformam os diferentes modelos de formação existentes.

O primeiro aspecto refere-se ao peso que se deve dar à formação prática e à formação teórica. Terezinha Nunes (1996), em artigo publicado na coletânea organizada pelo Nupes sobre o tema, comenta a evolução dos modelos de formação que predominaram na Inglaterra. Ela mostra como se evoluiu de uma concepção de professor como artesão, segundo a qual a formação era feita nas escolas, "aprendendo fazendo", para uma concepção de professor como profissional liberal, segundo a qual a formação é feita nas universidades, com sólida base teórica. Com as políticas neoliberais, tenta-se uma volta à concepção anterior, desvalorizando-se a formação na universidade. Note-se que, mesmo durante o predomínio da concepção de professor como profissional liberal, a proporção de tempo dedicado à formação teórica e prática nesse país era de $50 \%$ cada. Após muitas disputas, chegou-se recentemente à proporção de $2 / 3$ para a formação prática e $1 / 3$ para a teórica.

Outra autora, a inglesa Christine Pascal (1998), realizou um levantamento dos sistemas adotados pelos países da comunidade européia para a formação de professores de educação infantil e séries iniciais da escola elementar. Ela verificou que os países do norte da Europa dedicam mais tempo para a formação prática e os países do sul mais tempo para a formação teórica, sendo a Espanha o país que menos tempo reserva para a formação prática. Nós somos herdeiros dessa tradição, e até hoje não soubemos muito bem equacionar o lugar e a forma que essa formação prática deve ocupar nos currículos. Esse problema se acentua no caso do professor iniciante, para o qual não se prevê, no Brasil, nenhum tipo de transição até que adquira autonomia no seu trabalho. 
O segundo ponto relaciona-se à importância do conhecimento dos conteúdos do ensino diante do conhecimento dos alunos e de como eles aprendem. A importância do domínio sobre os conteúdos é evidente; entretanto, se em lugar de uma concepção pedagógica tradicional, na qual o papel do professor é central, adota-se uma concepção que entende os alunos como aprendizes ativos, tendo o professor o papel de criar condições favoráveis para a ampliação de seus conhecimentos $^{2}$ e de incentivo para que se tornem aprendizes inquisitivos, criativos e críticos, ao lado do domínio sobre os conteúdos é preciso que o professor conheça muito bem a fase de desenvolvimento em que os alunos se encontram, suas características culturais, sociais, étnicas, de gênero, de qual realidade eles partem e como aprendem.

Por outro lado, se incluímos na discussão o contingente de professores e educadores leigos, a maioria sem contar sequer com o nível básico de escolaridade, torna-se muito difícil adotar tanto as exigências de domínio dos conteúdos a serem trabalhados com os alunos, quanto as exigências de conhecimento das fases de desenvolvimento das crianças e de sua realidade cultural e social de uma perspectiva profissional, sem que se garanta, como ponto de partida, um patamar mínimo de instrução. ${ }^{3}$

Essa constatação aponta para o terceiro aspecto a ser considerado, que é o nível de ensino no qual se deve oferecer o curso de formação. Segundo a nova LDB, o Ensino Médio é a terceira etapa da educação básica. Assim, a formação específica para o magistério deveria ser pensada a partir desse nível básico de instrução, seja complementarmente ao Ensino Médio, seja em nível superior.

No caso dos educadores de creche, essa meta ainda está muito distante da realidade. Entretanto, esse fato deveria levar à previsão de fases de transição até que se alcancem as condições necessárias para que essa "subordem" profissional seja incorporada de fato ao perfil dos demais professores que trabalham com crianças na faixa etária de 0 a 10 anos. Essas fases intermediárias podem ser concebidas como módulos profissionalizantes de cursos supletivos, tanto do Ensino Fundamental quanto do Ensino Médio, como já se faz em algumas experiências no Brasil. ${ }^{4}$

Ao planejar essa transição, há outros aspectos a serem levados em consideração. Mudanças nos níveis de exigência para determinadas funções provocam conseqüências no perfil dos profissionais recrutados, 
que podem dificultar a presença de pessoas de grupos minoritários ou sub-representados da população (Mantovani e Tizard 1983), no caso do Brasil, negros, índios, mulheres mais velhas, entre outros.

Para garantir a representatividade desses grupos e a diversidade de origem dos educadores que trabalham com grupos infantis também diversos seria preciso desenvolver estratégias de discriminação positiva que operassem junto com as políticas de formação em níveis mais altos de escolaridade. Programas de formação em serviço que incluam o prosseguimento da escolaridade truncada dos professores leigos também podem desempenhar esse papel, ao assegurar-Ihes oportunidades de progressão na carreira vinculadas a novos patamares de instrução e qualificação alcançados por meio desses cursos.

O quarto aspecto a ser considerado é a especialização por faixa etária do aluno, dentro do intervalo mais amplo do nascimento aos 6 anos. Na maioria dos países há uma diversificação do tipo de formação prévia exigida dos professores e educadores que atendem bebês e crianças muito pequenas (até 2 ou 3 anos), crianças na faixa pré-escolar (dos $2 / 3$ anos até 5 ou 6 anos) e crianças de escola primária (dos 6/7 anos até os 10, 11 ou 12 anos, conforme o país).

No Brasil também se costuma admitir essa diferenciação, embora as redes de ensino muitas vezes não façam distinção ao recrutar professores para a pré-escola e a escola primária. No caso das creches, as diferenças ocorrem mais em conseqüência da falta de qualificação, havendo porém alguns profissionais formados em cursos livres para "berçaristas" ou equivalentes.

A proposta de currículo em estudo no Ministério da Educação (MEC 1997), no entanto, propõe exatamente a mesma formação para professores de educação infantil, séries iniciais do Ensino Fundamental, educação especial e ensino de jovens e adultos.

Seria muito importante que essa opção fosse reavaliada, propiciando uma flexibilidade ao curso, de forma que os futuros professores pudessem montar seu currículo a partir de um módulo básico e de disciplinas especializadas que os preparassem para o trabalho com diferentes tipos de alunos. Os sistemas de ensino poderiam então definir seus próprios critérios para admissão de novos professores ou para formação em serviço daqueles que já estão trabalhando, solicitando profissionais com tipos diversos de currículo, conforme a faixa etária dos alunos. Os professores que desejassem mudar de nível de 
ensino poderiam retornar ao curso de formação somente para aquelas disciplinas especializadas relacionadas ao novo tipo de aluno com o qual querem trabalhar.

Finalmente, em qualquer tipo de formação, seria muito importante que fosse contemplado um aspecto que costuma ser totalmente negligenciado nesses cursos: a formação para o trabalho com pais e comunidade. Na pesquisa relatada por Gatti e colaboradores (1994), os professores entrevistados queixam-se da falta de preparo para esse trabaIho. Também na Holanda, as pesquisas mostram que os professores não são preparados para o contato com os pais (Singer 1981).

Morsiani e Orsoni (1997) assim sintetizam o que se deve buscar obter com a formação prévia e em serviço dos professores. Segundo elas, que discutem especificamente o perfil dos professores de creche, estes devem:

a) saber: o que se refere aos conteúdos da formação de base e à importância da cultura, permitindo o confronto do conhecimento teórico com a situação real vivida com as crianças. Esse aspecto requer uma formação permanente que alimente a prática docente;

b) saber ser: para atingir essa meta é necessário que exista uma estrutura de apoio na instituição, que dê condições aos professores para lidar com o estresse, prevendo momentos de descanso e rodízio de funções;

c) saber interagir: os professores precisam interagir com vários "outros" e não só com o aluno. Sua competência social deve incluir o desempenho de seu papel na dinâmica da equipe de trabalho, em seu relacionamento com as famílias e os profissionais de outras agências educativas e sociais;

d) saber fazer: para desempenhar bem seu trabalho cotidiano, os professores precisam aprender a refletir sobre sua prática, construindo um projeto educativo próprio, utilizando a documentação, a avaliação, a pesquisa e a observação.

Embora pensado para as crianças menores, esse perfil parece desejável também para as séries iniciais do Ensino Fundamental, nas quais os professores acompanham as crianças nos diversos tipos de aprendizagem. Sínteses como essa podem nos ajudar a pensar em profissionais ao mesmo tempo equivalentes e diversos, superando a segregação das "ordens" tradicionais, mas sem abandonar o conhecimento acumulado em cada um desses campos. 


\section{Notas}

1. O uso do masculino genérico encobre o fato de que, trabalhando com essa faixa etária, há no Brasil apenas um pequeno contingente masculino, quase inexistente no caso das pré-escolas e creches. O leitor e a leitora notarão que, conforme o contexto, preferimos usar o masculino genérico ou o feminino.

2. Parece ser essa a concepção adotada pelos Parâmetros Curriculares Nacionais elaborados pelo MEC, para o Ensino Fundamental.

3. A LDB prevê a formação em nível superior, seja na universidade, seja nos Institutos Superiores de Educação. No entanto, a formação em nível médio continua a ser admitida para os professores de educação infantil e de $1^{\text {a }}$ a $4^{\text {a }}$ série do Ensino Fundamental.

4. Ver a proposta de curso supletivo de $1^{\circ}$ grau profissionalizante para educadoras de creche implantado em Belo Horizonte, descrito na publicação Textos FCC (14/97).

\section{The qualification of teachers for children from 0 to 10 years old: Discussing different models}

ABSTRACT: The article discusses the possibility of defining a new profile for teachers of early childhood education and the first four years of primary school. There are two different models of teachers that have emerged historically: the one qualified at the secondary level, that teaches all the subject matters, and the other that is qualified at the college or university level, that is especialized by different subjects. The first one works with preschool and primary school children. There is another kind of educator that work in day care centers; in Brazil they generally lack any kind of qualification. In the context of the recent legal and institutional reforms in the educational systems in Brazil, the article discusses the following aspects of the qualification of teachers for children up to 10 years of age: the relationships between theory and practice; the relationships between knowledge of the subjects contents and the knowledge about children's development; secondary or post secondary level of qualification; especialization by sub groups of age between the 0-10 group; and preparation for work with parents and the community. The article also stresses the importance of planning for the transition period until the new levels of qualification are attained. 


\section{Bibliografia}

BRASIL/MEC/SEF/DPEF/Coordenação geral de estudos e pesquisas. Referencial pedagógico-curricular para a formação de professores de educação infantil e séries iniciais do Ensino Fundamental. Brasília: MEC, 1997 (documento preliminar).

CAMPOS, Maria Malta. Educar e cuidar: questões sobre o perfil do profissional de educação infantil. In: MEC/SEF/Coedi. Por uma política de formação do profissional de educação infantil. Brasília: MEC/ SEF/Coedi, 1994.

CHARTIER, Anne-Marie. "A formação de professores na França e a criação dos Institutos Universitários de Formação de Mestres". In: WARDE, Mírian J. (org.). Novas políticas educacionais: Críticas e perspectivas. São Paulo: PUC, 1998.

FUNDAÇÃO CARLOS CHAGAS, Departamento de Pesquisas Educacionais. "Regulamentação da qualificação profissional do educador infantil: A experiência de Belo Horizonte". Textos FCC 14/97. São Paulo: Fundação Carlos Chagas, 1997.

GATTI, Bernardete. Formação de professores e carreira. Problemas e movimentos de renovação. Campinas: Autores Associados, 1997.

GATTI, Bernardete; ESPOSITO, Yara L. e SILVA, Rose N. "Características de professores(as) de $1^{\circ}$ grau no Brasil: Perfil e expectativas". Educação e Sociedade no 48. Campinas: CEDES, 1994.

HADDAD, Lenira. "A ecologia do atendimento infantil: Construindo um modelo de sistema unificado de cuidado e educação". Tese de doutorado. São Paulo: Faculdade de Educação, USP, 1997.

MANTOVANI, Susanna (org.). Bambino e societá. Verso una reforma dell'educazione prescolare. OCDE/Marietti, 1983.

MANTOVANI, Susanna e TIZARD, Jack. "Le istituzioni per la prima infanzia: Problemi aperti”. In: MANTOVANI, Susanna (org.). Bambino e societá. Verso una reforma dell'educazione prescolare. OCDE/ Marietti, 1983, pp. 27-59.

MORSIANI, Beatrice e ORSONI, Bianca. "La profissionalitè dell'educatore dell'asilo nido." In: BERTOLINI, Piero (org.). Nido e dintorni. Verso 
orientamenti educativi per le istituzioni della prima infanzia. Florença: La nuova Italia, 1997, pp. 229-241.

NUNES, Terezinha. "A experiência inglesa". In: MENEZES, Luis Carlos de (org.). Professores: Formação e profissão. Campinas: Autores Associados /Nupes/Unesco, 1996, pp. 87-119.

PASCAL, Christine e BERTRAM, Anthony. "A educação de crianças pequenas e de seus professores em três países europeus". In: ROSEMBERG, Fúlvia e CAMPOS, Maria M. (org.). Creches e préescolas no Hemisfério Norte. $2^{\mathrm{a}}$ ed. São Paulo: Cortez/Fundação Carlos Chagas, 1998, pp. 279-298.

POPKEWITZ, Thomas S. (comp.). Modelos de poder y regulación social en pedagogía. Crítica comparada de las reformas contemporáneas de la formación del profesorado. Barcelona: Pomares-Corredor, 1992.

SINGER, Elly. "Donne, bambini e centri per bambini". In: MANTOVANI, Susanna (org.). Bambino e societá. Verso una reforma dell'educazione prescolare. OCDE/Marietti, 1983, pp. 75-101.

UNESCO. Le monde de l'éducation, de la culture et de la formation. Março, 1998. Hors-série.

VERBA, Daniel. Le métier d'éducateur de jeunes enfants. Paris: Syros, 1993. 